\title{
Wunderlich's syndrome: \\ Three cases of acute spontaneous renal bleeding, conservately treated
}

\author{
Andrea Guttilla, Alessandro Crestani, Francesco Cattaneo, Fabio Zattoni, \\ Claudio Valotto, Massimo Iafrate, Fabrizio Dal Moro, Filiberto Zattoni \\ Urology Clinic, Department of Surgical, Oncological and Gastroenterological Sciences, \\ University of Padua, Italy.
}

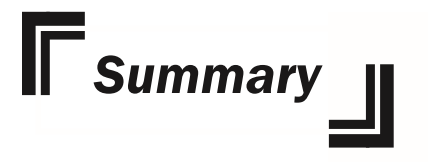

Wunderlich's syndrome is a clinical condition defined as a spontaneous renal bleeding of non traumatic origin, contained within the Gerota's fascia.

Wunderlich's syndrome is rare. Spontaneous bleeding of kidney tumors, either benign or malignant, represents the more common causes.

Classically it presents with acute flank pain, tender palpable mass and clinical hemodynamic deterioration. These symptoms are defined as the Lenk's classic triad. We present three cases of spontaneous renal bleeding.

KEY WORDS: Kidney; Spontaneous bleeding; Angiography; Kidney tumours.

\section{INTRODUCTION}

Wunderlich's syndrome is a clinical condition defined as a spontaneous renal bleeding of non traumatic origin, contained within the Gerota's fascia.

In 1700, Bonet was the first one who described this condition, while C.R.A. Wunderlich was the first to make a clinical description in 1856 (1). Coenen used the term Wunderlich's syndrome for the first time in 1910 (2).

Various authors find as underlying causes: nephritis, tumours, vascular diseases, cysts rupture (3-7).

Classically it presents with acute flank pain, tender palpable mass and clinical hemodynamic deterioration. These symptoms are defined as the Lenk's classic triad (8). We present three cases of spontaneous renal bleeding.

\section{Case 1}

A 72 years old man presented to the emergency department with severe generalized abdominal pain. He described a 3-hour history of acutely worsening abdominal and left lumbar pain and vomiting. Neither urinary symptoms nor history of trauma. He had a previous medical history positive for hypertension, dyslipidaemia and hyperuricemia. Clinically he had hypertension (160/100
$\mathrm{mmHg}$ ), tachycardia, a voluminous lumbar tumefaction and haematoma (Figure 1). Haemoglobin was $7.1 \mathrm{~g} / \mathrm{dL}$. A computed tomography $(\mathrm{CT})$ was performed, showing a

\section{Figure 1.}

Case 1: voluminous lumbar tumefaction and haematoma.

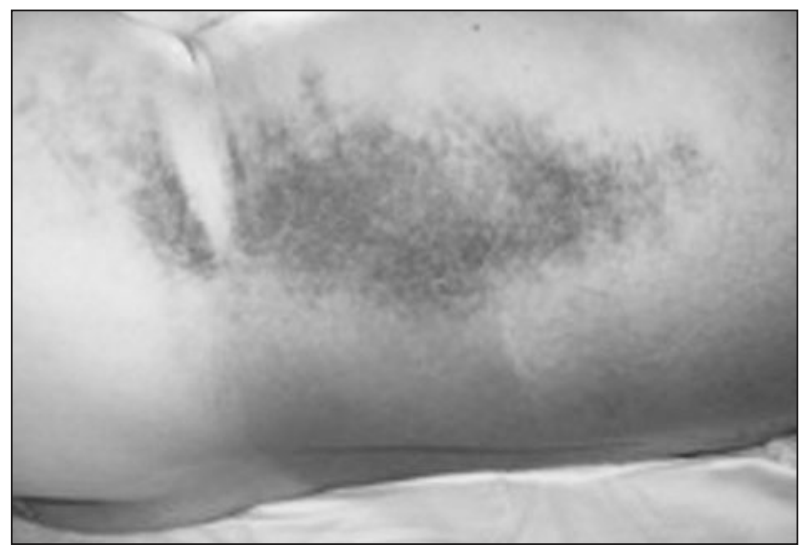


large $(16 \mathrm{~cm})$ left perinephric haematoma with an active bleeding in the sub capsular and perirenal space. Normal controlateral kidney (Figure 2).

The patient's haemoglobin levels continued to decrease, and he was transfused with 4 units of blood.

The patient underwent emergency embolization (Figure 3) of a 3-cm avascular area in the left kidney at the middle third (possible sub capsular lesion) with an active bleeding from a thin arterial capsular branch of the lower renal pole.

Then, he was admitted to the Intensive Care Unit (ICU) for close observation and strict bed-rest. His haemoglobin level stabilized, and he was treated conservatively. He was discharged from the Urology Department after 30 days.

CT scans before leaving the hospital and the one made after 90 days showed significant reduction of the perirenal haematoma (Figures 4, 5).

One year after the patient is fine. The haematoma is completely disappeared (Figures 6, 7). He still has problems of blood pressure that he is controlling with different drugs.

\section{Case 2}

A 75 years old woman presented to the emergency department with severe left lumbar pain.

Neither urinary symptoms nor history of trauma. She had a previous medical history positive for ischemic heart disease, atrial fibrillation in therapy with anticoagulants, hypertension, cronic kidney failure with an atrophic right kidney.

Clinically he had hypotension (110/70 $\mathrm{mmHg}$ ), tachycardia, haemoglobin $7 \mathrm{~g} / \mathrm{dL}$, serum creatinine $300 \mathrm{mmol} / \mathrm{L}$.

The patient's haemoglobin levels continued to decrease, and she was transfused with 5 units of blood.

The patient underwent a CT scan that showed an important lumbar haematoma (Figure 8).

The patient underwent emergency renal arteriography that described: stenosis of the left renal artery, with

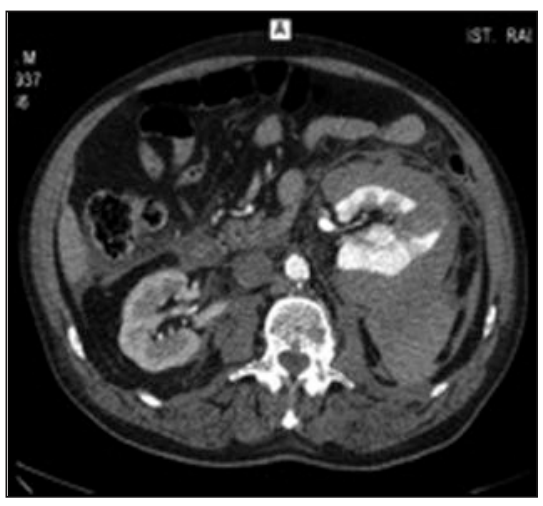

Figure 2.

Case 1: computed tomography (CT) showing a large $(16 \mathrm{~cm})$ left perinephric haematoma with an active bleeding in the sub capsular and perirenal space.

Figure 3.

Case 1: emergency embolization of a 3-cm avascular area in the left kidney at the middle third (possible sub capsular lesion) with an active bleeding from a thin arterial capsular branch of the lower renal pole.

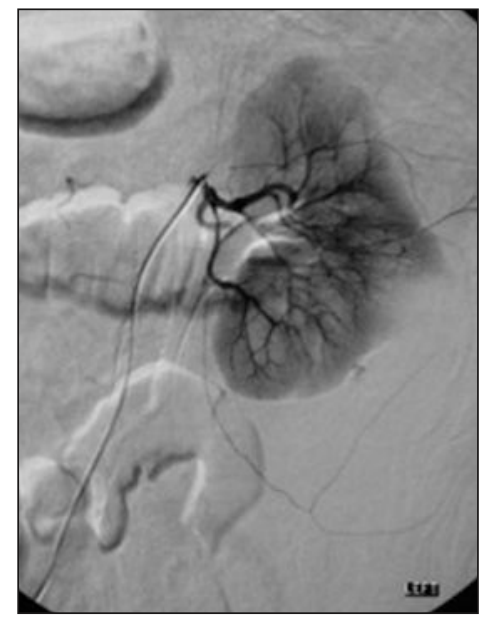

Figures 4-5.

Case 1: CT scans at dismissal and after 90 days showed significant reduction of the perirenal haematoma.
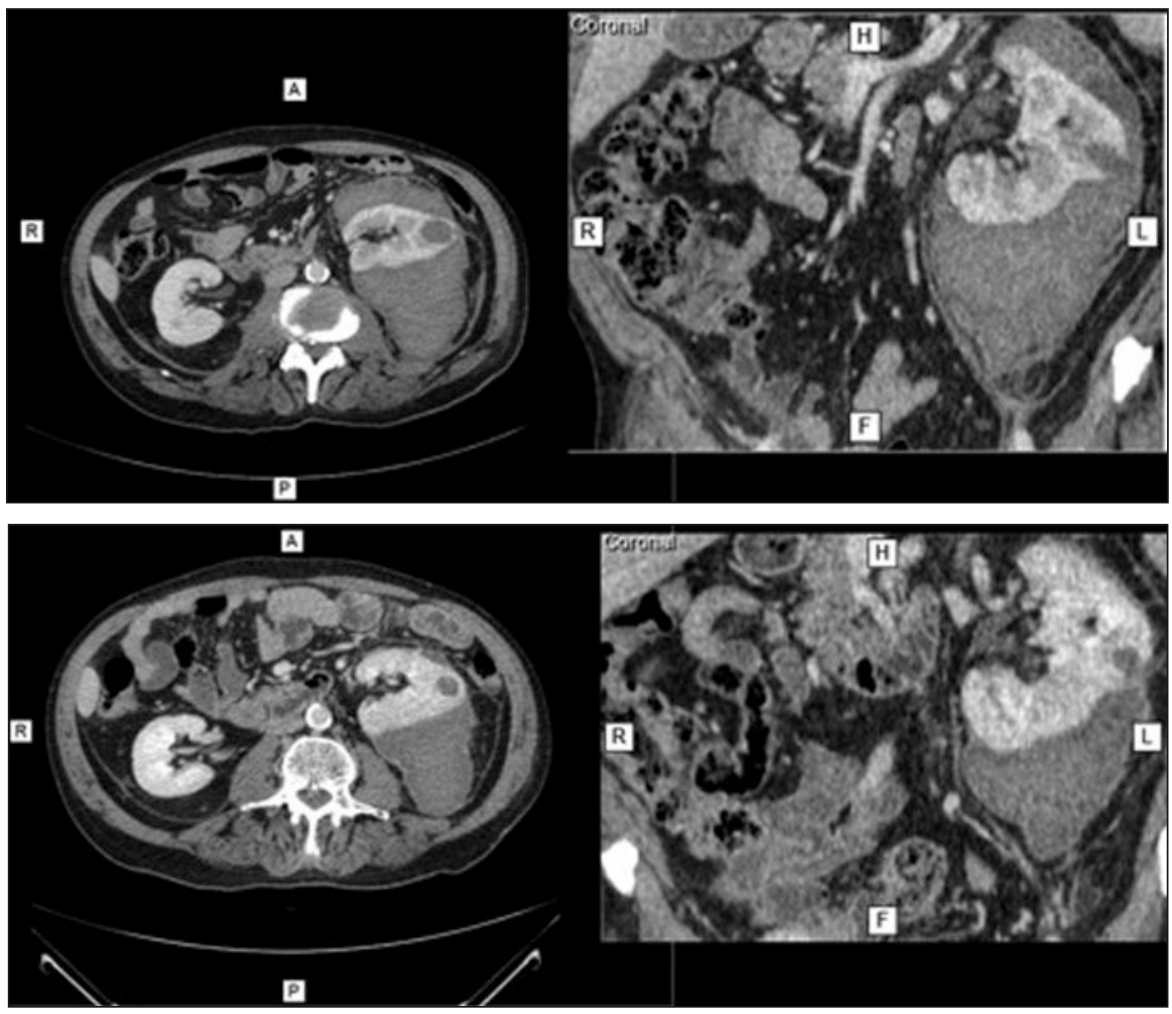

no parenchymal vascularisation. The left artery was embolized with kidney exclusion. Then, she was admitted to the ICU for close observation and strict bed-rest. The haemoglobin levels during the staying in the ICU 
Figures 6-7.

Case 1: CT scan after 1 year showing that haematomais completely disappeared.
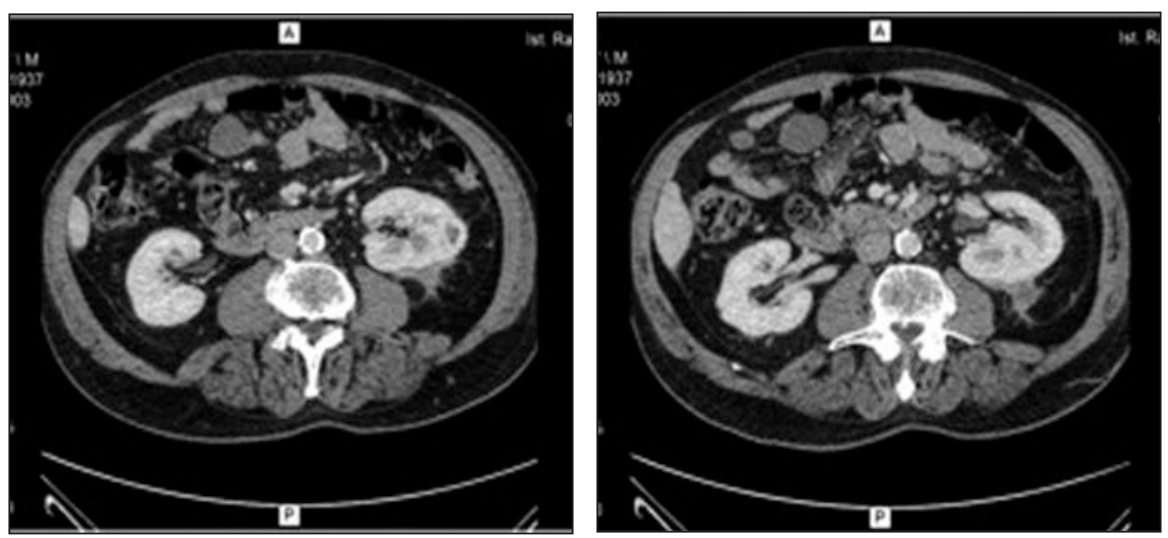

Figure 8.

Case 2: CT scan showing an important lumbar haematoma.

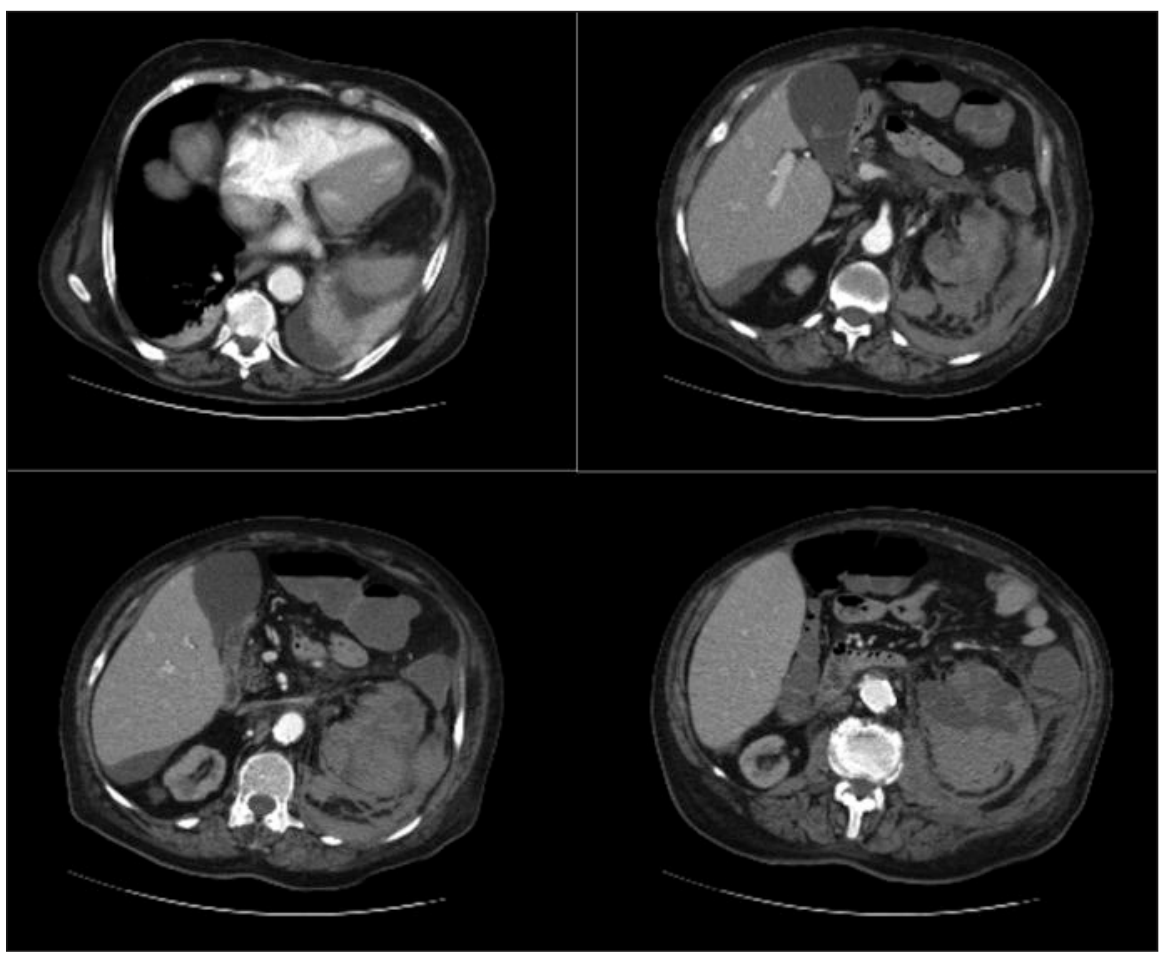

evidence of active bleeding and a $6 \mathrm{~cm}$ sub capsular mass. Normal contralateral kidney.

We decided to treat him conservately and to treat the mass surgically after the acute problem was resolved. He was discharged from the Urology Department after 12 days. CT scan before leaving the hospital showed significant reduction of the perirenal haematoma and confirmed the presence of a solid area.

One month after, the patient underwent open right partial nephrectomy. The pathological report showed a type 2 papillary RC, Fuhrman grade 3, pTlaNx.

\section{Discussion}

Wunderlich's syndrome is a rare syndrome, with about 300 cases described in the literature. The most common causes of these spontaneous haemorrhages are represented by neoplasm (61\%) (9). As benign lesion, angiomyolipoma $(31.5 \%)$ is the most common, while renal cell carcinoma is the most common malignant one $(10,11)$. Some authors have also described some other different causes as vasculitis, arteriovenous fistulas, rupture of renal artery aneurism rupture and nephritis (12).

The imaging studies, for patient with suspicious of a spontaneous renal bleeding, are CT scan or angiography $(9,10)$. CT scan can give the opportunity to know the entity of the haematoma and the presence of an active bleeding. Selective angiography with embolization is often useful in the acute phase of the haemorrhage in order to control bleed-

started to rise up. She was discharged from the Urology Department after 12 days with haemoglobin value of $10.3 \mathrm{mg} / \mathrm{dl}$.

The patient was lost at follow-up.

\section{Case 3}

A 57 years old man presented to the emergency department with acute right lumbar pain.

Neither urinary symptoms nor history of trauma. He had a previous medical history positive for hypertension. Clinically he had normal blood pressure (140/80 mmHg). Haemoglobin was $12.1 \mathrm{~g} / \mathrm{dL}$. A CT was performed, showing a large $(10 \mathrm{~cm})$ right perinephric haematoma with no ing, contribute to diagnosis and reduce the need for surgery. The management is dictated by the clinical condition of the patient and by the underlying aetiology. Sometimes subjects with unstable haemodynamic condition can require an emergency nephrectomy especially if the cause of the bleeding is clear (i.e. renal cancer). In other cases, as the one described above, a conservative treatment to preserve renal function can be the best choice. Also in kidney bleeding following a trauma, many Authors recommend a conservative treatment if major complications, as other abdominal injuries, are not present $(13,14)$

Eventually, if the imaging done during the follow-up shows a clear diagnosis a nephrectomy must be per- 
formed. The follow-up, after patient discharge, should be done with $\mathrm{CT}$ scans to monitor the haematoma reduction and with measurements of blood pressure to exclude Page syndrome $(15,16)$.

\section{Conclusion}

Wunderlich's syndrome is rare. Spontaneous bleeding of kidney tumours, either benign or malignant, represents the more common cause.

CT scan and angiography are the preferred diagnostic tools. The treatment must be tailored for single cases. Conservative treatment with a periodic follow-up is often a feasible approach.

\section{RefEREnCES}

1. Wunderlich CRA. Handbuch der Pathologie und Therapie. 2nd ed. Stuttgart, Ebner \& Seubert, 1856.

2. Bilesio AE, Campodonico A, Molina R. Síndrome périrrenal espontaneo (síndrome de Wunderlich). Rev Urol. 1962; 2:17.

3. Hao LW, Lin CM, Tsai SH. Spontaneous hemorrhagic angiomyolipoma present with massive hematuria leading to urgent nephrectomy. Am J Emerg Med. 2008; 26:249 e3-5.

4. Pummer K, Lammer J, Wandschneider G, Primus G. Renal cell carcinoma presenting as spontaneous retroperitoneal haemorrhage. Int Urol Nephrol. 1990; 22:307-11.

5. McDougal WS, Kursh ED, Persky L. Spontaneous rupture of kidney with perirenal hematoma. J Urol. 1975; 114:181-184.
6. Cinman AC, Farrer J, Kaufman JJ. Spontaneous perinephric hemorrhage in 65-year old man. J Urol. 1985; 133:829-832.

7. Belville JS, Morgentaler A, Loughlin KR, Tumeh SS. Spontaneous perinephric and subcapsular renal hemorrhage: evaluation with CT, US, and angiography. Radiology. 1989; 172:733-738.

8. Flageat J, Vicens JL, Cosnard G, Foster D, Metges PJ. Hématome périrrénal reévelateur d'une périartérite nouse. J Radiol. 1986; $67: 419-422$

9. Zhang JQ, Fielding JR, Zou KH. Etiology of spontaneous perirenal hemorrhage: a meta-analysis. J Urol. 2002; 167:1593-6.

10. Sebastia MC, Perez-Molina MO, Alvarez-Castells A, et al. CT evaluation of underlying cause in spontaneous subcapsular and perirenal hemorrhage. Eur Radiol. 1997; 7:686-90.

11. Oon SF, Murphy M, Connolly SS. Wunderlich syndrome as the first manifestation of renal cell carcinoma. J Urol 2010; 7:129-32.

12. Albi G, del Campo L, Tagarro D. Wünderlich's syndrome: causes, diagnosis and radiological management. Clin Radiol. 2002; 57:840-5.

13. Moudouni SM, Patard JJ, Manunta A, et al. A conservative approach to major blunt renal lacerations with urinary extravasation and devitalized renal segments. BJU Int. 2001; 87:290-4.

14. Husmann DA, Gilling PJ, Perry MO, et al. Major renal laceration with a devitalized fragment following blunt abdominal trauma: a comparison between nonoperative (expectant) versus surgical management. J Urol. 1993; 150:1774-7.

15. Wein AJ, Kavoussi LR Campbell-Walsh Urology 9th edition, Saunders/Elsevier, 2007, p.170.

16. Monstrey SJ, Beerthuizen GL, Vanderwerken C, et al. Renal trauma and hypertension. J Trauma. 1989; 29:65-6.

\author{
Correspondence \\ Andrea Guttilla, MD (Corresponding Author) \\ andrea.guttilla@gmail.com \\ Alessandro Crestani, MD \\ alessandro.crest@gmail.com \\ Francesco Cattaneo, MD \\ i.francescocattaneo@gmail.com \\ Fabio Zattoni, MD \\ fabiozattoni@gmail.com \\ Claudio Valotto, MD \\ claudio.valotto@sanita.padova.it \\ Massimo Iafrate, $M D$ \\ massimo.iafrate@unipd.it \\ Fabrizio Dal Moro, MD \\ fabrizio.dalmor@gmail.com \\ Filiberto Zattoni, MD \\ filiberto.zattoni@unipd.it \\ Urology Clinic, Department of Surgical, \\ Oncological and Gastroenterological Sciences, University of Padua, \\ Via Giustiniani, 2 - 35100 Padua, Italy
}

